Editorial

\title{
Nuevos modelos experimentales para el estudio de la función y disfunción hematopoyética: diferenciación "in vitro" de células madre embrionarias
}

La hematopoyesis es el proceso de generación, regulación y mantenimiento de producción de las células sanguíneas, desde etapas embrionarias muy tempranas hasta el final de la vida. La práctica hematológica se viene beneficiando, quizás como ninguna otra especialidad clínica, de conocimientos básicos generados por la investigación no solo de la hematopoyesis experimental, sino también de la biología celular y molecular. Por ejemplo, la identificación de las alteraciones moleculares subyacentes a determinados procesos neoplásicos ha llevado al diseño inteligente de nuevos fármacos contra dichas dianas moleculares; y el desciframiento de los procesos involucrados en la respuesta immune ha permitido alcanzar mayores índices de éxito en terapias que contemplan el transplante hematopoyético. En cuanto a los aspectos puramente científicos de los fundamentos moleculares y celulares de la formación de la sangre, bien es cierto que es uno de los sistemas biológicos más prolijamente estudiados. Es quizás, por ello, por lo que la hematopoyesis nos suena a viejo conocido y que los esfuerzos parezcan centrarse en la ampliación y mejora de las aproximaciones terapeúticas actualmente en uso.

Sin embargo, y tomando prestado el discurso de George Daley*, hay problemas en hematología que no se podrán resolver insistiendo en las prácticas actuales. Este notable investigador de la Harvard Medical School, en una reciente revisión en Blood, hace un excelente alegato a favor del uso de las células troncales embrionarias humanas (hES, del ingles human Embryonic Stem cells) para clonación terapeútica hematológica. El autor brinda argumentos de gran interés que abogan por la conveniencia de seguir explorando nuevos caminos que amplíen los ámbitos de aplicación y de éxito de los protocolos de reemplazo de la función hematopoyética. Por ejemplo, contrapone las ventajas indudables de los transplantes autólogos frente a los problemas inherentes a los transplantes alogénicos, incluídos los de donante relacionado, como son el importante porcentaje de recaídas, el fracaso de implante o secuelas no relacionadas. Y esto sin contar el alto índice de posibles huéspedes que no encuentran donante idóneo o de enfermos con ciertas dolencias congénitas con un inaceptable riesgo de sufrir la enfermedad aguda de injerto contra huesped. Es por ello, por lo que Daley contempla como una posibilidad altamente atractiva la generación de tejido hematopoyético genéticamente idéntico al huésped a partir de células ES, derivadas de embriones donantes, pero que contengan el material genético del propio paciente.

Las células troncales (o madre) hematopoyéticas (HSC, del ingles Hematopoietic Stem Cells) mantienen la capacidad de generar (y regenerar en huéspedes no relacionados) todos los linajes circulantes, por lo que se consideran multipotentes. Gracias a un grupo de técnicas refinadas, entre las cuales se encuentra la citometría de flujo o los ensayos clonogénicos, se han podido identificar y aislar -aunque esto no es estrictamente necesario para su uso en transplante- no solo de médula ósea del adulto, sino también de sangre de cordón umbilical y de sangre periférica de adultos previamente movilizados, por ejemplo con citoquinas mitogénicas. Estas tres fuentes de HSCs son las utilizadas para el transplante hematopoyético y gracias al uso de modelos animales, concretamente el ratón, se ha incrementado de manera exponencial el conocimiento sobre su biología. Por ejemplo, se sabe que son muy escasas en número dentro de los órganos hematopoyéticos de los mamíferos, pero que tienen la cualidad, aunque limitada, de proliferación, y por tanto de perpetuación de su potencial regenerador. Desde luego, el uso de animales inmunosuprimidos como receptores de HSCs se ha impuesto como método ineludible para la evaluación del potencial auto-regenerador y multipotencial de células aisladas, expandidas o generadas "ex vivo". En otra vertiente de la hematopoyesis experimental, la disponibilidad de ani-

\footnotetext{
* Scientific and clinical opportunities for modeling blood disorders with embryonic stem cells. M. William Lench and George Q. Daley, Blood, vol. 107, pp 2605-2612. 2006.
} 


\section{Calés Bourdet}

males modificados genéticamente, a través de la ganancia o la pérdida de función de determinados genes (transgénicos o "knock-out", respectivamente), ha permitido identificar algunas de las proteínas esenciales para la doble función, autorenovación y multipotencialidad, de estas células.

Por su parte, las células madre embrionarias ES mantienen íntegra la capacidad de autorenovación y la de generar cualquier tipo celular del individuo adulto, es decir, son totipotentes (si no se tiene en cuenta tejidos extraembrionarios). Es indudable la importancia que han tenido las de ratón (mES) a la hora de hacer posible la generación de líneas de animales modificados genéticamente, gracias a que se pueden mantener en cultivo de manera indefinida y con sus propiedades íntegras. Pero también han permitido el diseño de estrategias dirigidas a generar diferentes tipos celulares "in vitro" y desde luego, entre otros, el hematopoyético, para el cual las células ES presentan una mayor capacidad de especificación. A pesar de los decepcionantes primeros intentos de producir "in vitro" células equiparables a las HSCs a partir de células ES -solo se consiguió repoblación hematopoyética a corto plazo en huéspedes murinos irradiados a dosis letales-, existe la evidencia actual de que es posible generar HSCs a partir de células mES, con capacidad repobladora a largo plazo, esto es en huéspedes primarios y secundarios. Por su parte, y a lo largo de sus ocho años de existencia, se ha podido comprobar la capacidad de células ES humanas para generar células hematopoyéticas "in vitro" y a pesar de que la repoblación "in vivo" es muy limitada, su similitud con las murinas hace pensar que será posible generar HSCs a partir de células hES.

Estas células ES se establecen como línea celular (es decir, con capacidad de ser mantenida indefinidamente) a partir de blastocistos generados por fertilización in vitro y donados para la investigación biomédica. De esta manera, se han aislado hES portadoras de defectos congénitos, de gran utilidad para profundizar en los aspectos patofisiológicos de las correspondientes enfermedades, y también líneas correspondientes a individuos normales. Esto podría hacer pensar en blastocistos donados como posible fuente de células para terapia, aunque por su inherente escasez y especial siesgo, no parece ser una propuesta excesivamente realista. Las hES normales ya establecidas pueden ser modificadas genéticamente por introducción/reposición de genes individuales y, al sostener programas de diferenciación y especialización celular, podrían ser sustratos para posibles terapias regenerativas. Sin embargo, el método más certero para conseguir células con características génicas definidas ha sido la fusión celular, lo cual lleva a alteraciones cromosómicas groseras (aneuploidías) lo que las hace, al tiempo que valiosas herramientas para la investigación básica, dudosas alternativas para terapias de reposición. El tercer método posible para obtener células hES genéticamente definidas es la transferencia nuclear, mediante la cual el núcleo de un oocito es reemplazado por el núcleo de otra célula. Si ésta es una célula somática de un individuo adulto, como fue en el caso de la oveja Dolly, el oocito así producido se puede considerar idéntico al que generó, en primera instancia, al individuo donante. Es por este potencial, el de posible método de clonación de individuos, por lo que se han levantado grandes polémicas a la hora de autorizar este tipo de abordajes. Además, el reciente escándalo surgido por la retirada (forzada) de una publicación en la que un grupo de investigadores coreanos pretendidamente mostraban la obtención de líneas hES derivadas de diferentes pacientes, no ha contribuído a fortalecer ese tipo de aproximaciones. Sin embargo, la posibilidad de obtener un tipo de células, totalmente compatibles con el enfermo (ya que serían genéticamente idénticas) y con el potencial de derivar HSCs capaces de repoblar efectivamente la función hematopoyética, hace de esta vía una alternativa muy atractiva. Por supuesto, es necesario reclamar un especial rigor y dedicación por parte de los investigadores básicos, para asegurar que todos los posibles problemas ad latere, por ejemplo posibles riesgos contraídos en los cultivos y manipulaciones "in vitro", sean estrictamente controlados y evaluados, antes de emprender tareas más cercanas a la clínica. Una de las ventajas con las que partimos es la amplia experiencia acumulada en la hematopoyesis experimental utilizando modelos animales: los resultados podrán ser amplia y fiablemente contrastados. Uno de los atributos de los viejos conocidos.

Carmen Calés Bourdet, PhD Instituto de Investigaciones Biomédicas "Alberto Sols"

Departamento de Bioquímica Universidad Autónoma de Madrid Madrid (España) 